\title{
Pengaruh Label Halal, Asosiasi Merek, Iklan, dan Celebrity Endroser terhadap Keputusan Pembelian (Survei Pada Konsumen Wardah Di Malang)
}

Premi Wahyu Widyaningrum

Fakultas Ekonomi, Universitas Muhammadiyah Ponorogo

E-mail : premi.wahyu@gmail.com

\begin{abstract}
Moslem consumers tend to choose products that are declared halal compared with products that have not been declared halal by the authorities. No exception in terms of cosmetic purchase. Cosmetics is one such purchase that emphasizes emotional engagement, so sometimes idol figures (celebrities) who become brand ambassadors in a cosmetic ad can stimulate purchases. Halal Label Relationships with Advertisements, Celebrity Endrosers, Brand Associations, and Purchase Decisions are how marketers create halal and certified products so that Muslim consumers feel protected to consume them. The purpose of this study is to determine the factors that affect consumer purchasing decisions on Wardah cosmetic products. This type of research is explanatory with quantitative approach and survey method. The research location is in Malang Town Square with total sample of 57 respondents. The findings indicate that there is a positive and significant influence among the variables studied.
\end{abstract}

Keyword: Halal Lable, Brand Asosiation, Ads, Celebrity Endroser, Purchase Decisions

\begin{abstract}
ABSTRAK
Konsumen Islam cenderung memilih produk yang dinyatakan halal dibandingkan dengan produk yang belum dinyatakan halal oleh lembaga berwenang. Tidak terkecuali dalam hal pembelian kosmetik. Kosmetik adalah salah satu pembelian yang menekankan keterlibatan perasaan (emosional), sehingga terkadang figur atau tokoh idola (selebriti) yang menjadi brand ambassador pada suatu iklan kosmetik dapat menstimulan pembelian. Hubungan Label Halal dengan Iklan, Celebrity Endroser, Asosiasi Merek, serta Keputusan Pembelian adalah bagaimana pemasar menciptakan produk yang halal dan bersertifikat sehingga konsumen muslim merasa terlindungi untuk mengkonsumsinya. Tujuan dari penelitian ini adalah untuk mengetahui faktor yang mempengaruhi Keputusan Pembelian konsumen pada produk kosmetik Wardah. Jenis penelitian ini adalah eksplanatori dengan pendekatan kuantitatif dan metoder survei. Lokasi penelitian berada di Malang Town Square dengan jumlah sampel sebanyak 57 orang responden. Hasil temuan menunjukkan bahwa terdapat pengaruh yang positif dan signifikan diantara variabel yang diteliti.
\end{abstract}

Keyword: Label Halal, Asosiasi Merek, Iklan, Celebrity Endroser, Keputusan Pembelian 
Premi, Pengaruh Label Halal, Asosiasi Merek, Iklan, dan Celebrity Endroser pada Keputusan Pembelian

\section{PENDAHULUAN}

Kehalalan akan menjadi penting dalam kajian pemasaran di Indonesia, karena saat ini konsumen akan memperhatikan label halal yang tertera pada produk yang diperjual belikan pada pasar. Ummat muslim percaya bahwa dengan mengkonsumsi makanan yang halal akan menjadi berkah dan sehat untuk manusia. Kehalalan merupakan pokok utama bagi umat muslim untuk beribadah agar senantiasa manusia selalu dijalan yang benar, disamping itu kehalalan tertera dalam hadist dan Alquran. Islam mengajarkan kita agar senantiasa untuk mengkonsumsi yang ada dimuka bumi yang serba halal dan baik, baik makanan dan minuman bahkan selain itu seperti kosmetik, obat-obatan dan lain-lainnya. Kosmetik dan obat-obatan keduanya disebut halal apabila bahan-bahan yang terkandung dalam keduanya harus dari bahan baku pilihan yang sesuai syariat Islam dan memiliki sertifikat halal dari Majelis Ulama Indonesia.

Menurut Sumarwan (2011, h.209) konsumen Islam cenderung memilih produk yang dinyatakan halal dibandingkan dengan produk yang belum dinyatakan halal oleh lembaga berwenang. Kesadaran akan mengkonsumsi produk halal pada konsumen muslim, akibat dari pemahaman agama yang baik dan edukasi produsen mengenai sertifikat halal pada produknya. Hal ini akan berdampak pada semakin tingginya konsumen yang perduli tentang sertifikat label halal pada produk yang dibelinya, karena saat ini banyak konsumen yang semakin kritis dan memiliki pengetahuan produk yang baik sebelum melakukan keputusan pembelian.

Wanita cenderung membelanjakan uangnya lebih banyak untuk penampilan seperti pakaian, alat-alat perawatan, kecantikan rambut dan sebagainya (Kasali,1998:34). Didukung oleh pendapat Belch \& Belch (2001,h.159), kosmetik adalah salah satu pembelian yang menekankan keterlibatan perasaan (emosional), sehingga terkadang figur atau tokoh idola yang menjadi brand ambassador pada suatu iklan kosmetik dapat menstimulan pembelian.

Pemilihan selebriti dalam penyampaian pesan tersebut nantinya diharapkan dapat menimbulkan dampak yang cepat dalam brand awareness dan brand recognition. 
Premi, Pengaruh Label Halal, Asosiasi Merek, Iklan, dan Celebrity Endroser pada Keputusan Pembelian

Ketepatan memilih sumber pesan (Endorser) dapat didasarkan pada atribut yang melekat pada Endorser tersebut (Shimp, 2003: 460). Dalam hal ini kosmetik Wardah yang menjadi obyek penelitian menggunakan beberapa selebriti yang memiliki kesan religius seperti Dewi Sandra, Inneke Koesherawati, Lisa Namuri dan Dian Pelangi (Momzhak, 2015).

Selebriti yang dipilih Wardah sebagai Endorser memiliki citra dan kesan diri yang dianggap mewakili nilai-nilai dari produk Wardah, sejauh ini menggunakan Celebrity Endorser dalam mengkampanyekan pesan dari kosmetik halal dianggap cukup berhasil. Ketika pesan iklan itu berhasil, maka konsumen akan mengasosiasikan kosmetik halal dengan Wardah pada benak mereka.

Faktor resiko yang tinggi seringkali dikalahkan oleh tampilan iklan, apalagi iklan produk-produk kosmetik yang ditawarkan, terlihat begitu menjanjikan suatu perubahan penampilan. Natalia \& Pramadi dalam Pertiwi (2009:6) menyatakan bahwa kosmetik merupakan sarana yang digunakan wanita untuk mewujudkan bayangan dirinya seperti yang diinginkannya. Churchill dalam
Pertiwi (2009:6), mengatakan bahwa wanita mempunyai kebiasaan mendengar atau membaca iklan, sehingga wanita lebih mudah dipengaruhi oleh iklan dan pada akhirnya akan mudah juga dipengaruhi minat membelinya. Shimp (2003:374) menyatakan iklan dapat mempengaruhi pengharapan konsumen tentang suatu produk, dan menggerakkan untuk melakukan pembelian.

Menurut Solomon (2002) proses keputusan pembelian yang dilakukan oleh seorang konsumen melalui lima tahapan, yaitu pengenalan masalah, pencarian informasi, evaluasi alternatif, pembelian dan perilaku pasca pembelian. Konsumen dalam melakukan keputusan pembelian dapat dipengaruhi salah satunya oleh keterlibatan yang dirasakan oleh konsumen terhadap produk yang akan mereka beli. Pengaruh perasaan atau afeksi pada konsumen menjadi peluang bagi perusahaan untuk mempengaruhi proses keputusan pembelian mereka. Memanfaatkan keunggulan media televisi, beberapa di antaranya seperti iklan dapat mendramatisir tampilannya ataupun visualisasi kreatif hingga menarik (format iklan), pemaparan keung- 
Premi, Pengaruh Label Halal, Asosiasi Merek, Iklan, dan Celebrity Endroser pada Keputusan Pembelian

gulan produk (isi pesan), kemudahan memahami informasi yang ada dalam iklan (struktur pesan), serta penggunaan model iklan yang menarik, ataupun pemberian testimoni (sumber pesan). Lebih jauh lagi iklan berfungsi sebagai stimuli. Pengelolaan stimuli iklan inilah yang menjadi ujung tombak iklan dalam mempengaruhi penerima pesan.

Kosmetik Wardah memberikan jaminan kenyamanan bagi konsumen melalui jaminan kehalalan produk kosmetiknya yang membantu konsumen terhindar dari penggunaan bahan yang diragukan kehalalannya (Satyahadi, 2013). Tentunya kita tidak ingin melanggar apa yang telah disyariatkan oleh agama dalam mengkonsumsi suatu produk sehingga membuat kita tidak nyaman dalam menggunakannya. Salah satu upaya yang dilakukan kosmetik Wardah adalah dengan menyelenggarakan berbagai kampanye. Wardah selalu menjadikan filosofi mereknya, yaitu Earth, Love, Life sebagai nyawa dalam setiap kampanyenya.

Peneliti ini mengambil obyek penelitian pada konsumen Malang Town Square (Matos) karena pada Matos terdapat Wardah Store (toko offline resmi dari kosmetik Wardah), selain itu terdapat beberapa counter Wardah lainnya pada Matahari Matos dan Hypermarket Matos. Matos merupakan pusat perbelanjaan yang sangat popular bagi masyarakat Kota Malang. Oleh karena itu peneliti mendapatkan peluang yang lebih besar untuk meneliti konsumen kosmetik Wardah pada lokasi penelitian yang peneliti tetapkan.

Berdasarkan latar belakang masalah di atas dan untuk memperjelas pokok pembahasan pada penelitian ini, maka masalah dalam penelitian ini dapat dirumuskan sebagai berikut:

1. Apakah label halal berpengaruh terhadap keputusan pembelian?

2. Apakah asosiasi merek berpengaruh terhadap keputusan pembelian?

3. Apakah iklan berpengaruh terhadap keputusan pembelian?

4. Apakah Celebrity Endorser berpengaruh terhadap keputusan pembelian?

Maka yang menjadi tujuan dalam penelitian ini adalah:

1. Menganalisis dan menjelaskan bahwa label halal berpengaruh terhadap keputusan pembelian. 
Premi, Pengaruh Label Halal, Asosiasi Merek, Iklan, dan Celebrity Endroser pada Keputusan Pembelian

2. Menganalisis dan menjelaskan bahwa Asosiasi Merek berpengaruh terhadap keputusan pembelian.

3. Menganalisis dan menjelaskan bahwa iklan berpengaruh terhadap keputusan pembelian.

4. Menganalisis dan menjelaskan Celebrity Endorser berpengaruh terhadap keputusan pembelian.

\section{METODE PENELITIAN}

Penelitian ini termasuk penelitian eksplanatoris (explanatory research) dengan pendekatan kuantitatif, yaitu penelitian yang berupaya menjelaskan hubungan kausal antara variabelvariabel melalui pengujian hipotesis (Singarimbun dan Effendi, 1995). Pendekatan kuantitatif dilandasi pada suatu asumsi bahwa suatu gejala itu dapat diklasifikasikan, dan hubungan gejala bersifat kausal (sebab akibat) antara variabel atau konstruk melalui pengujian hipotesis (Sugiyono, 2010).

Metode penelitian yang digunakan penelitian menggunakan metode survei, yaitu metode yang digunakan untuk memperoleh informasi melalui permintaan keterangan-keterangan kepada responden dengan menggunakan kuesioner sebagai alat pengumpul data utama (primer). Pada umumnya yang merupakan unit analisis dalam penelitian survei adalah individu (Singarimbun dan Effendi, 1995). Unit analisis dalam penelitian ini adalah konsumen kosmetik Wardah pada Malang Town Square (MATOS).

Penelitian ini menganalisis bukti data primer yang dikumpulkan dari konsumen kosmetik Wardah pengunjung Matos. Penelitian ini bertempat di Malang Town Square, tepatnya di J1. Veteran No. 2, Penanggungan, Klojen, Kota Malang, Jawa Timur 65111.

Populasi adalah wilayah generalisasi yang terdiri atas objek/ subjek yang mempunyai kualitas dan karakteristik tertentu yang ditetapkan oleh peneliti untuk dipelajari dan kemudian ditarik kesimpulannya (Sugiyono, 2010). Populasi dalam penelitian ini adalah seluruh konsumen kosmetik Wardah di Malang.

Metode pengambilan sampel yang digunakan adalah metode probability sampling. Probabilitas sampling adalah teknik pengambilan sampel yang memberi peluang atau kesempatan yang sama bagi setiap anggota populasi yang terpilih sebagai sampel penelitian (Sugiyono, 
Premi, Pengaruh Label Halal, Asosiasi Merek, Iklan, dan Celebrity Endroser pada Keputusan Pembelian

2008). Teknik pengambilan sampel yang digunakan dalam penelitian ini adalah simple random sampling (pengambilan sampel acak sederhana), yang merupakan bagian dari probability sampling.

Jumlah populasi dalam penelitian ini tidak diketahui, maka untuk menentukan jumlah sampel digunakan rumus Machin and Cham-bell (1997; 169). Berdasarkan pertimbangan bahwa nilai terendah yang diperkirakan akan diperoleh melalui penelitian ini adalah $\mathrm{r}=0,45$; kemudian $\alpha=0,5$ Z1- $\alpha=1,645$ pada pengukuran dua arah, dan $\beta=0,10$ $\mathrm{Z} 1-\beta=1,645$ maka diperoleh $\mathrm{n}$ $($ minimum $)=57,41$. Sehingga dalam penelitian ini mengambil sampel minimal 57 orang responden. Dalam penelitian ini kriteria sampel merupakan konsumen kosmetik Wardah di Malang.

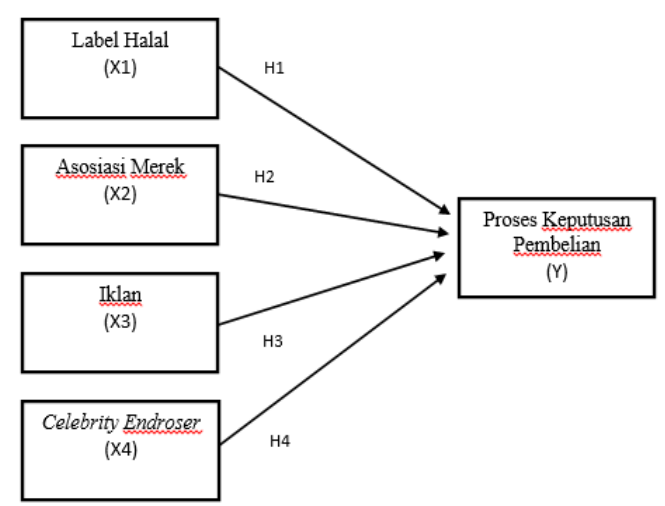

Gambar 1 Model Hipotesis
Gambar diatas menunjukkan model hipotesis dari penelitian ini. Sedangkan rumusan hipotesisnya adalah sebagai berikut:

H1: Label halal berpengaruh positif dan signifikan terhadap keputusan pembelian.

$\mathrm{H} 2$ : Asosiasi merek berpengaruh positif dan signifikan terhadap keputusan pembelian.

H3: Iklan berpengaruh positif dan signifikan terhadap keputusan pembelian.

H4: Celebrity Endroser berpengaruh positif dan signifikan terhadap keputusan pembelian.

Metode analisis data yang digunakan untuk membuktikan hipotesis yang diajukan dalam penelitian ini menggunakan General-ized Structured Component Analysis (GSCA). GSCA dikembangkan oleh Heungsun Hwang, Hec Montreal, dan Yhoshio Takene pada 2004. Tujuannya adalah menggantikan faktor dalam kombinasi linier dari indikator (variabel manifes) di dalam analisis SEM (Solimun, 2012). Tenehaus (2008) dalam Solimun (2012) mengatakan bahwa GSCA adalah metode baru SEM berbasis komponen, sangat penting dan dapat digunakan untuk 
Premi, Pengaruh Label Halal, Asosiasi Merek, Iklan, dan Celebrity Endroser pada Keputusan Pembelian

perhitungan skor (bukan skala) dan juga dapat diterapkan pada sampel yang sangat kecil. Di samping itu, GSCA dapat digunakan pada model struktural yang melibatkan variabel dengan indikator refleksif dan atau formatif.

Fungsi atau kegunaan GSCA adalah untuk mendapatkan model struktural yang powerfull guna tujuan konfirmasi. Oleh karena itu, metode GSCA adalah setara dengan analisis model struktural berbasis kovarians (SEM). Dengan demikian analisis GSCA juga power-full untuk menguji model berbasis teori, atau dengan kata lain untuk mengkonfirmasi teori tentang hubungan antar variabel yang terdapat di dalam model struktural (Solimun, 2012).

Variabel penelitian terdiri atas empat variabel laten eksogen, dan tiga variabel laten endogen. Pengujian hipotesis dalam penelitian menggunakan GSCA dengan software GeSCA. Langkah-langkah pemodelan persamaan struktural GSCA mirip dengan PLS (Solimun, 2012). Langkah tersebut seperti dapat dilihat pada gambar berikut ini:

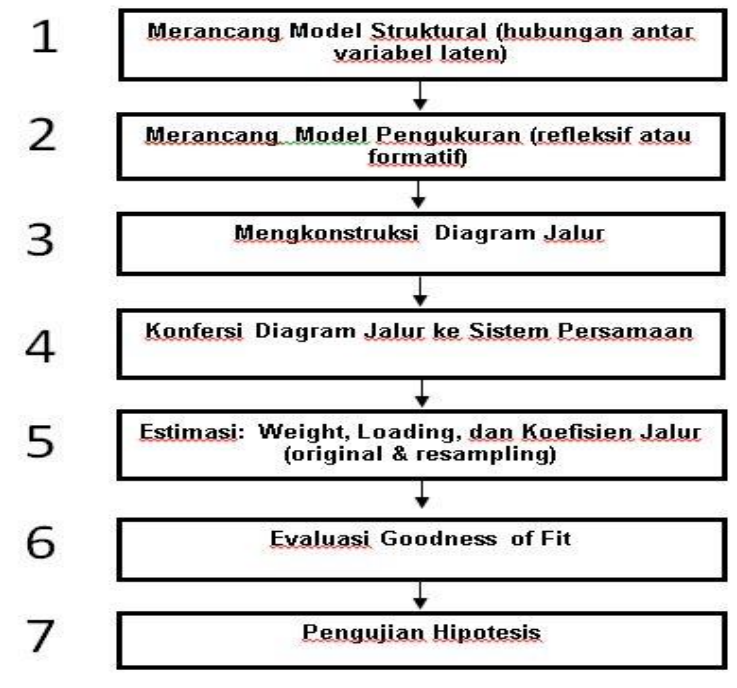

Gambar 2 Langkah Analisis GSCA

HASIL DAN PEMBAHASAN

Responden dalam penelitian ini adalah konsumen kosmetik Wardah di Malang yang sedang berada di Malang Town Square. Total kuesioner yang disebarkan adalah 57 lembar. Adapun rincian kuesioner disajikan pada tabel di bawah ini:

Tabel 1 Distribusi Kuesioner

\begin{tabular}{|c|c|c|c|c|}
\hline \multirow[t]{2}{*}{ Hari } & \multirow[t]{2}{*}{ Jumlah } & \multicolumn{2}{|c|}{ Kembali } & \multirow{2}{*}{$\begin{array}{l}\text { Tidak } \\
\text { Kembali }\end{array}$} \\
\hline & & Baik & Rusak & \\
\hline 1 & 10 & 10 & 0 & 0 \\
\hline 2 & 8 & 8 & 0 & 0 \\
\hline 3 & 8 & 8 & 0 & 0 \\
\hline 4 & 9 & 9 & 0 & 0 \\
\hline 5 & 11 & 11 & 0 & 0 \\
\hline 6 & 5 & 5 & 0 & 0 \\
\hline 7 & 6 & 6 & 0 & 0 \\
\hline & 57 & \multicolumn{2}{|c|}{ Total } & 0 \\
\hline
\end{tabular}


Premi, Pengaruh Label Halal, Asosiasi Merek, Iklan, dan Celebrity Endroser pada Keputusan Pembelian

Hasil pengujian validitas untuk item pernyataan yang digunakan dalam mengukur variabel menunjukkan nilai korelasi yang lebih besar dari nilai r-tabel yang ditentukan. Dengan demikian dapat dikatakan bahwa seluruh item pernyataan yang digunakan dalam mengukur variabel tersebut telah menunjukkan tingkat ketepatan yang cukup baik (valid). Sedangkan pengujian reliabilitas seluruh item yang digunakan dalam mengukur variabel dependent dan independent menghasilkan koefisien reliabilitas (cronbach's alpha) diatas 0.6 sehingga dapat dikatakan bahwa instrumen yang digunakan untuk mengukur seluruh variabel tersebut dinyatakan memiliki reliabilitas yang tinggi. Dengan kata lain instrumen yang digunakan tersebut telah menunjukkan konsistensi pengukuran pada semua respondennya.

Tabel 2 Model FIT GSCA

\begin{tabular}{|c|c|}
\hline \multicolumn{2}{|c|}{ Model Fit } \\
\hline FIT & 0.725 \\
\hline AFIT & 0.708 \\
\hline GFI & 0.982 \\
\hline SRMR & 0.224 \\
\hline NPAR & 100 \\
\hline
\end{tabular}

FIT menunjukkan varian total dari semua variabel yang dapat dijelaskan oleh model tertentu. Nilai FIT berkisar dari 0 sampai 1. Jadi, model yang terbentuk dapat menjelaskan semua variabel yang ada sebesar 0.725. Keragaman label halal, asosiasi merek, iklan, celebrity endroser, dan proses keputusan pembelian yang dapat dijelaskan oleh model adalah sebesar $72.5 \%$ dan sisanya $(27.5 \%)$ dapat dijelaskan oleh variabel yang lain. Artinya, jika dilihat dari nilai FIT yang diperoleh, model yang terbentuk dapat dikatakan bagus. Semakin besar nilai FIT yang diperoleh maka model yang ada akan semakin bagus.

Adjusted dari FIT hampir sama dengan FIT. Namun, karena variabel yang mempengaruhi proses keputusan pembelian tidak hanya satu sehingga akan lebih baik apabila interpretasi tentang ketepatan model menggunakan FIT yang sudah terkoreksi atau menggunakan AFIT. Karena semakin banyak variabel yang mempengaruhi maka nilai FIT semakin besar karena proporsi keragaman juga akan meningkat sehingga untuk menyesuaikan dengan variabel yang ada dapat menggunakan FIT yang sudah terko- 
Premi, Pengaruh Label Halal, Asosiasi Merek, Iklan, dan Celebrity Endroser pada Keputusan Pembelian

reksi. Jika dilihat dari nilai AFIT, keragaman label halal, asosiasi merek, iklan, Celebrity Endroser, dan proses keputusan pembelian yang dapat dijelaskan oleh model adalah sebesar $70.8 \%$ dan sisanya $(29.2 \%)$ dapat dijelaskan oleh variabel yang lain. Artinya, jika dilihat dari nilai AFIT yang diperoleh, model yang terbentuk bagus.

GFI (Unweighted least-squares) dan SRMR (standardized root mean square residual). Keduanya sebanding dengan perbedaan antara kovarian sampel dan kovarian yang diproduksi oleh pendugaan parameter GSCA. GFI dekat dengan nilai 1 dan nilai-nilai SRMR mendekati 0 dapat diambil sebagai indikasi cocok. Pada permasalahan ini nilai SRMR $=0,224$ sehingga model yang terbentuk dapat dikatakan telah sesuai. Data stastistik juga menunjukkan nilai $\mathrm{GFI}=0,982$ maka model dikatakan sesuai.

Hasil analisis masing-masing jalur menggunakan software GSCA dapat dilihat pada gambar berikut ini:

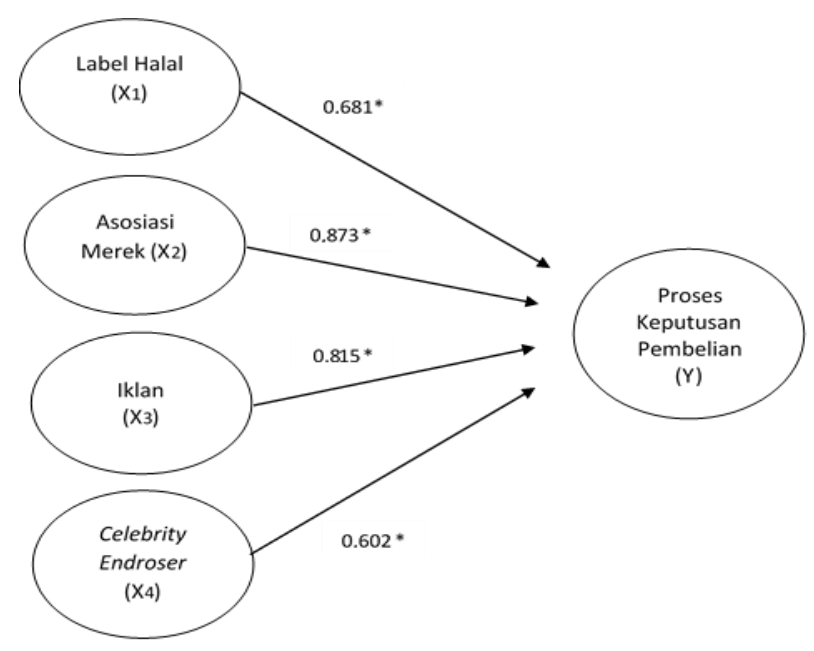

Gambar 3 Model Empiris Penelitian

Hipotesis 1: Label halal terhadap proses keputusan pembelian

Hipotesis H1 menyatakan bahwa label halal berpengaruh signifikan terhadap proses keputusan pembelian. Hasil pengujian model menggunakan variabel pengalaman sebagai moderasi dengan GSCA menunjukkan bahwa hasil positif dan signifikan dengan nilai critical rasio sebesar 2.57 dan koefisien jalur sebesar 0.681, sehingga dapat disimpulkan bahwa label halal memiliki pengaruh yang signifikan dengan proses keputusan pembelian. Hasil penelitian ini sejalan dengan hasil penelitian Stefani (2013), Nur (2014) Wahyu (2013), dan Mahdi (2015).

Wahyu budi Utami (2013) melakukan penelitian kepada konsumen 
Premi, Pengaruh Label Halal, Asosiasi Merek, Iklan, dan Celebrity Endroser pada Keputusan Pembelian

kosmetik Wardah di Yogyakarta.

Hasil temuannya mengindikasikan bahwa label halal yang digunakan produk kosmetik Wardah akan menstimulus konsumen untuk melakukan keputusan pembelian, terutama untuk konsumen muslim. Hasil temuan Premi (2016) juga menunjukkan hal yang sama. Data empiris penelitian menunjukkan label halal berpengaruh signifikan terhadap keputusan pembelian.

\section{Hipotesis 2: Asosiasi merek terha-} dap proses keputusan pembelian

Hipotesis $\mathrm{H} 2$ menyatakan bahwa asosiasi merek berpengaruh signifikan terhadap proses keputusan pembelian. Hasil pengujian memperoleh bukti empiris bahwa $\mathrm{H} 2$ berpengaruh positif dan signifikan. Artinya, semakin tinggi asosiasi merek semakin tinggi pula proses keputusan pembelian. Hasil pengujian model menggunakan variabel pengalaman moderasi dengan GSCA menunjukkan bahwa hasil pengujian berpengaruh positif dan signifikan dengan nilai critial ratio sebesar 3.89 dan koefisien jalur sebesar 0.873 . Hal ini konsisten dengan hasil penelitian Stefani (2013), dan Premi (2013).
Stefani (2013) menjelaskan bahwa asosiasi merek merupakan pendorong konsumen dalam melakukan pembelian. Apabila merek suatu produk sudah tertanam di benak konsumen, hal ini akan menjadi pilihan pertama bagi konsumen tersebut untuk melakukan pembelian. Menurut Premi (2013) ekuitas merek menjadi determinan proses keputusan Pembelian konsumen.

\section{Hipotesis 3: Iklan terhadap proses} keputusan pembelian

Hipotesis H3 menyatakan bahwa iklan berpengaruh signifikan terhadap proses keputusan pembelian. Hasil pengujian memperoleh bukti empiris bahwa $\mathrm{H} 3$ berpengaruh signifikan. Artinya, semakin tinggi iklan semakin tinggi pula proses keputusan pembelian. Hasil pengujian model menggunakan variabel pengalaman moderasi dengan GSCA menunjukkan bahwa hasil pengujian berpengaruh signifikan dengan nilai critial ratio sebesar 3.14 dan koefisien jalur sebesar 0.815. Hasil penelitian ini sejalan dengan hasil penelitian Stefani (2013) dan Nur (2014).

Nur (2014) dalam penelitiannya pada konsumen Wardah Yayasan 
Premi, Pengaruh Label Halal, Asosiasi Merek, Iklan, dan Celebrity Endroser pada Keputusan Pembelian

Pondok Pesantren Putri An-Nuriyah menjelaskan bahwa advertising memberikan pengaruh yang besar terhadap keputusan pembelian. Beberapa studi yang lain juga menunjukkan bukti empiris bahwa iklan berpengaruh positif terhadap keputusan pembelian. Bukti empiris ini memiliki implikasi bahwa konsumen akan cenderung melakukan pembelian apabila produsen menggunakan iklan pada waktu dan tempat yang tepat.

\section{Hipotesis 4: Celebrity endroser terhadap proses keputusan pem- belian}

Hipotesis H4 menyatakan bahwa celebrity endroser berpengaruh signifikan terhadap proses keputusan pembelian. Hasil pengujian diperoleh bukti empiris bahwa $\mathrm{H} 4$ berpengaruh positif dan signifikan. Artinya, semakin tinggi celebrity endroser semakin tinggi pula proses keputusan pembelian. Hasil pengujian model menggunakan variabel pengalaman moderasi dengan GSCA menunjukkan bahwa hasil pengujian berpengaruh signifikan dengan nilai critial ratio sebesar 2.18 dan koefisien jalur sebesar 0.602. Hal ini konsisten dengan hasil penelitian Stefani (2013) dan Premi (2016).

Stefani (2013) dalam penelitiannya pada konsumen kosmetik berlabel halal di Jakarta menemukan bukti bahwa celebrity endroser merupakan faktor penting bagi keputusan pembelian. Bukti empiris menunjukkan bahwa celebrity endroser berpengaruh positif dan signifikan pada keputusan pembelian. Penelitian Premi (2016) juga menyatakan hasil yang sama dan serupa.

\section{Tabel 3 Pengujian Structural Model}

\begin{tabular}{|l|l|l|l|}
\hline \multicolumn{4}{|c|}{ Path Coefficients } \\
\hline & Estimate & SE & CR \\
\hline $\begin{array}{l}\text { Label Halal->Proses } \\
\text { Keputusan Pembelian }\end{array}$ & 0.681 & 0.535 & $2.57^{*}$ \\
\hline $\begin{array}{l}\text { Asosiasi Merek-> Proses } \\
\text { Keputusan Pembelian }\end{array}$ & 0.873 & 0.270 & $3.89^{*}$ \\
\hline $\begin{array}{l}\text { Iklan-> Proses } \\
\text { Keputusan Pembelian }\end{array}$ & 0.815 & 0.429 & $3.14^{*}$ \\
\hline $\begin{array}{l}\text { Celebrity Endroser-> } \\
\text { Proses Keputusan } \\
\text { Pembelian }\end{array}$ & 0.602 & 0.111 & $2.18^{*}$ \\
\hline
\end{tabular}

Dari hasil pembahasan di atas, terdapat beberapa keterbatasan dalam penelitian ini. Keterbatasan tersebut antara lain:

1. Penelitian ini bukan merupakan penelitian eksperimen atau bersifat longitudinal tetapi penelitian eks- 
Premi, Pengaruh Label Halal, Asosiasi Merek, Iklan, dan Celebrity Endroser pada Keputusan Pembelian

planatori dan dalam jangka waktu singkat. Sehingga penelitian ini tidak mampu menggambarkan dinamika objek yang diteliti bila dibandingkan dengan penelitian dalam satu periode proses keputusan pembelian.

2. Sampel pada penelitian ini memiliki ukuran yang kecil, sehingga tidak menutup kemungkinan bahwa dapat membatasi generalisasi hasil penelitian.

3. Kemungkinan terjadi systematic error baik yang disengaja maupun tidak disengaja yang disebabkan oleh peneliti (seperti: desain kuesioner yang kurang baik) dan juga pada saat pengambilan data (seperti mengarahkan responden) serta kesalahan dari responden (seperti tidak mengerti kuesioner, menebak jawaban).

\section{KESIMPULAN DAN SARAN}

Dari hasil penelitan dengan judul "Pengaruh label halal, asosiasi merek, iklan, dan celebrity endroser terhadap keputusan pembelian (Survei pada konsumen Wardah di Malang) menggunakan alat analisis GSCA dapat disimpulkan beberapa hal yaitu:
1. Semua variabel yang diuji dalam model mempunyai hubungan yang positif. Dapat dikatakan bahwa jika salah satu variabel mengalami kenaikan, maka memberikan pengaruh kenaikan juga pada variabel yang lain.

2. Hasil penelitian menunjukkan bahwa penggunaan label halal, asosiasi merek, iklan, dan celebrity endroser secara tepat, efektif dan efisien akan memberikan stimulus yang besar pada konsumen dalam proses keputusan pembelian kosmetik Wardah.

Berdasarkan hasil penelitian, saran yang perlu dipertimbangkan yakni:

1. Peneliti selanjutnya dapat melakukan pengumpulan data dengan menggunakan penggabungan instrumen lain selain kuesioner, seperti wawancara mendalam dengan responden maupun dengan pihak produsen kosmetik Wardah sehingga dapat diperoleh informasi dan gambaran variabel-variabel dan hubungannya secara lebih jelas.

2. Berdasarkan keterbatasan penelitian di atas, peneliti selanjutnya disarankan untuk mengambil objek 
Premi, Pengaruh Label Halal, Asosiasi Merek, Iklan, dan Celebrity Endroser pada Keputusan Pembelian

penelitian dan jumlah sampel yang berbeda untuk mengkaji model secara lebih mendalam, serta diharapkan akan memperoleh hasil yang maksimal.

3. Bagi produsen kosmetik Wardah, disarankan untuk tetap memelihara kualitas pelayanan terhadap konsumen dengan memperhatikan segala aspek. Konsumen yang merasa puas terhadap produk kosmetik Wardah akan menjadi konsumen tetap produk itu sendiri, dan tidak akan berpindah ke produk kosmetik yang lain.

\section{DAFTAR RUJUKAN}

Aaker, David .A. 1991. Managing Brand Equity. The Free Press. New York.

Azize, Nur, (2014), Pengaruh Advertising dan Label Halal Terhadap Keputusan Pembelian Produk Kosmetik Wardah di Yayasan Pondok Pesantren Putri An-Nuriyah, Universitas Islam Negeri Sunan Ampel Surabaya.

Belch, George E. \& Michael A. Belch. 2001. Introduction Ad and Promotion. An Integrated Marketing. McGraw Hill Company.

Borzooei, Mahdi and Maryam Asgari, (2015), Country-ofOrigin Effect on Consumer Purchase Intention of Halal
Brands, American Journal of Economics, Finance and Management, 1(2), 25-34.

Burhanuddin, (2011), Pemikiran Hukum Perlindungan Konsumen dan Sertifikat Halal, (h.140,h.142), Universitas Islam Negeri Maulana Malik Ibrahim Maliki Press. Malang.

Kasali, Rhenald. 1992. Manajemen Periklanan Konsep dan Aplikasinya di Indonesia. Jakarta: PT Pustaka Utama Grafiti.

Kotler, Philip and Keller Kevin Lane. 2009. Principles of Marketing.. 13th Edition. Prentice Hall. New Jersey.

Levy, Miachael and B.A Weitz. 2012. Retailing Management. McGraw Hill Irwin. New York.

Momzhak, (2015), http://www. halabea.com/2015/10/daftarkosmetik-halal-terlengkap2015.html, diakses $10 \mathrm{Mei}$ 2016.

Pertiwi, Dewi Damayanti. 2009. Hubungan Antara Kepercayaan Diri dengan Minat Membeli Kosmetik pada Konsumen Klinik Kecantikan. Fakultas Psikologi. Universitas Muhammadiyah Surakarta. (diakses tanggal 3 Juni 2016)

Qardhawi,Yusuf. (2007), Halal dan Haram dalam Islam, (h.5), Era Intermedia. Surakarta. 
Premi, Pengaruh Label Halal, Asosiasi Merek, Iklan, dan Celebrity Endroser pada Keputusan Pembelian

Satyahadi, Alfred,. (2013), http://www.indonesiaprintme dia.com/pendapat/225pentingnya-penggunaanlabel-pada-kemasan.html, diakses 10 Mei 2016.

Shimp, Terence A. 2003. Periklanan Promosi dan Aspek Tambahan Komunikasi Pemasaran Terpadu. Edisi Ke-5, Jilid I. Alih Bahasa: Revyani Sahrial, Dyah Anikasari. Editor: Nurcahyo Mahanani. Jakarta: Erlangga.

Singarimbun, Masri dan Sofian Effendi. 2011. Edisi Editor. Metode Penelitian Survai. Edisi Revisi. LP3ES. Jakarta.

Solimun. 2012. Penguatan Confirmatory Reseach Pemodelan Persamaan Struktural Generalized Structured Componeny Analysis GSCA. Program Studi Statistika FMIPA Universitas Brawijaya. Malang.

Solomon, $R \quad$ Michael. 2002. Consumer Behavior; Buying Having and Being. Prentice Hill Pearson .New Jersey.

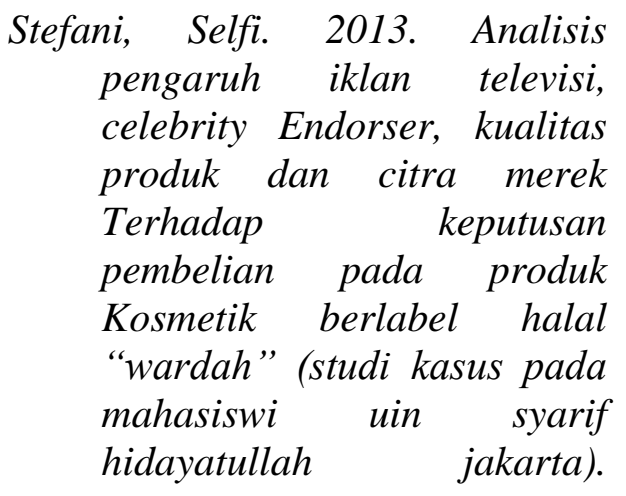

Skripsi: uin syarif hidayatullah. Jakarta.

Sugiyono. 2008. Metode Penelitian Bisnis (Pendekatan Kuantitatif, Kualitatif dan R\&D). Alfabeta. Bandung.

Sugiyono. 2010. Metode Penelitian Bisnis: Pendekatan Kuantitatif, Kualitatif, dan $R \& D, \quad$ edisi kelimabelas. Alfabeta. Bandung.

Sumarwan, Ujang. 2011. Perilaku konsumen: teori dan penerapannya dalam pemasaran. Ghalia Indonesia. Bandung.

Supriadi, Cecep,. (2014), http://www.marketing.co.id/w ardah-lari-kencang-bersamakomunitas/. diakses $10 \mathrm{Mei}$ 2016.

Utami, Wahyu budi, (2013), Pengaruh Label Halal Terhadap Keputusan Pembelian (Survei Pembeli Kosmetik Wardah Dioutlet Wardah Griya Muslim AnNisa Yogyakarta), Universitas Islam Negeri Sunan KalijagaYogyakarta.

Widyaningrum, Premi wahyu, 2016. Pengaruh Label Halal dan Celebrity Endorser terhadap Keputusan Pembelian (Survei pada Konsumen Wardah di Ponorogo). Jurnal Jesi vol.6 no.2. 2016.

Widyaningrum, Premi wahyu, Achmad Fauzi dan Zainul Arifin. 2013. Pengaruh 
Premi, Pengaruh Label Halal, Asosiasi Merek, Iklan, dan Celebrity Endroser pada Keputusan Pembelian

\begin{abstract}
Ekuitas Merek Terhadap Minat Pembelian Serta Dampaknya Terhadap Keputusan Pembelian (Survey pada Konsumen Smartphone BlackBerry Pengunjung Malang Plaza). Jurnal Profit: Vol. 7 No.2, Th 2013.
\end{abstract}

Yuswohady, (2015), http://www. yuswohady.com/2015/07/04/h alal-marketing/,diakses $\quad 10$ Mei. 

